\title{
Induction and Habituation of Immediate Early Gene Expression in Rat Brain by Acute and Repeated Restraint Stress
}

\author{
Kathleen R. Melia, ${ }^{1}$ Andrey E. Ryabinin,, ${ }^{1,2}$ Richard Schroeder, ${ }^{1}$ Floyd E. Bloom, ${ }^{1}$ and Michael C. Wilson' \\ 'Department of Neuropharmacology, The Scripps Research Institute, La Jolla, California 92037 and ${ }^{2} \mathrm{P}$. K. Anokhin \\ Institute of Normal Physiology, Russian Academy of Medical Sciences, Moscow, Russia 103009
}

\begin{abstract}
Acute exposure to stress leads to activation of the pituitaryadrenal axis (PA-axis) while repeated exposure to a homotypic stressor generally results in habituation of this response. Previous studies suggested that such habituation is largely due to changes in afferents of the PA-axis. To examine where within these afferents habituation occurs, we studied the effect of acute and repeated exposure to 2 hr restraint stress on expression of c-fos mRNA, as a marker of altered neuronal activity, in brain regions previously shown to influence the activity of the PA-axis. Acute restraint stress increased expression of c-fos mRNA in cortex, hippocampus, hypothalamus, septum, and brainstem. In contrast, the effect of restraint stress on c-fos expression in the aforementioned brain regions was much smaller in animals restrained once daily for $4 \mathrm{~d}$, and nonexistent in animals restrained once daily for $9 \mathrm{~d}$. A similar pattern of induction and habituation of jun-B, but not zif-268, $C$-jun, or jun-D mRNA expression, was observed in the cortex of animals exposed to acute versus repeated restraint stress. The habituation of c-fos responses was stressor specific: exposure of restraint-adapted animals to a novel (20 $\mathrm{min}$ swim) stress produced an increase in levels of $c$-fos mRNA in every examined brain region comparable to that seen in animals exposed to this stressor for the first time. Adrenalectomy did not alter the pattern of c-fos expression induced by acute and repeated restraint stress. Therefore, activation and habituation of these c-fos responses are independent of changes in circulating levels of corticosterone.
\end{abstract}

[Key words: immediate early genes, c-fos, restraint stress, habituation, swim stress, adrenalectomy]

Physiological responses to acute physical or psychological stressors are generally adaptive: organs and systems that promote vigilance and strength are activated while those systems involved in homeostatic functions are inhibited (Aserita, 1985). Thus, acute stressors increase cardiac output, cause a shunting of blood from the periphery to muscles, and increase glycolysis, lipolysis, and protein breakdown to release energy stores, while suppressing digestive, bladder, gallbladder, and immune func-

\footnotetext{
Reccived Nov. 29, 1993; revised Feb. 25, 1994; accepted Mar. 29, 1994

We thank Dr. George Koob and Danny Abat for the use of facilities and friendly cooperation. The work was supported by NARSAD and MacArthur Foundation Depression Network, NIAAA-Narcology Center Exchange Program, and NIAAA 06420 Research Grant.

Correspondence should be addressed to Dr. Andrey E. Ryabinin, CVN9, Department of Neuropharmacology, The Scripps Research Institute, 10666 North Torrey Pines Road, La Jolla, CA 92037.

Copyright (C) 1994 Society for Neuroscience $0270-6474 / 94 / 145929-10 \$ 05.00 / 0$
}

tions (Yates et al., 1980; Munck et al., 1984; Aserita, 1985). Activation of the pituitary-adrenal axis by acute stressors, resulting in increased plasma levels of adrenocorticotrophin (ACTH) and corticosterone (CORT), is pivotally involved in this constellation of responses that advance the preservation of organisms (Selye, 1936, 1952; Cannon, 1939; Mason, 1968; Yates et al., 1980; Munck et al., 1984). In contrast, extended or extreme physical or psychological stress has long been associated with a number of pathological conditions including cardiac disease, chronic hypertension, diabetes mellitus, gastrointestinal and peptic ulceration, and increased susceptibility to infection, autoimmune discase, and cancer (cf. Ramsey, 1982). Chronic stress has also been implicated in the pathogenesis of psychiatric disorders such as schizophrenia, amphetamine-induced psychosis, and panic, anxiety, eating, and depressive disorders (Redmond and Huang, 1979; Loyd, 1980; Breslau and Davis, 1986; Krystal et al., 1989). Interestingly, the latter four disorders are also associated with marked dysregulation of the PA-axis (Holsboer et al., 1989; Smith et al., 1989; Johnson et al., 1992).

Under certain conditions, influenced by the intensity (Natelson et al., 1988; Pitman et al., 1990) and frequency of the stressor (De Boer et al., 1990) and the genetic composition, history, and current status of the organism, habituation to chronic stress occurs protecting the organism from further physiological and/ or psychological insult. For example, acute exposure to $2.5 \mathrm{hr}$ restraint stress markedly activates the PA-axis, resulting in increased plasma ACTH and CORT levels, while presentation of this same stressor daily for $10-14 \mathrm{~d}$ results in a decrement in the magnitude of these responses (Armario et al., 1988; Hauger et al., 1990). Daily exposure to $2 \mathrm{hr}$ restraint stress for $1-4$ weeks (Natelson et al., 1988) or $6 \mathrm{hr}$ restraint stress for 4-5 weeks (Hashimoto et al., 1988) also produces habituation of these responses. Similar habituation of CORT responses occurs when rats are repeatedly exposed to $15 \mathrm{~min}$ water immersion (De Boer et al., 1990).

It is possible that by determining the biochemical and intracellular alterations that mediate habituation of the PA-axis we may facilitate our understanding of those psychiatric disorders characterized, at the physiological level, by dysregulation of this axis. However, the cellular and molecular mechanisms underlying this phenomenon have previously received little attention and are not well understood. To some extent habituation occurs within the axis itself. Thus, glucocorticoids released in response to stressor presentation inhibit the synthesis and release of the primary ACTH secretagogue, corticotropin-releasing hormone (CRH), from the hypothalamic paraventricular nucleus, and of ACTH from corticotrophs in the anterior pituitary (cf. Keller- 
Wood and Dallman, 1989; Harbuz and Lightman, 1992). Moreover, concentrations of pituitary CRH receptors in animals exposed to repeated or prolonged stress are reduced by $26-48 \%$ (Hauger et al., 1988, 1990). Surprisingly, however, these animals are actually equally or more responsive to a novel acute stressor (Hauger et al., 1988, 1990), or to exogenous CRH (Hauger et al., 1988) than are non-stress-adapted rats. In fact, results from a number of studies have clearly established that habituation to repeated or prolonged presentation of a single (homotypic) stressor does not generalize to other (heterotypic) stressors. For example, rats exposed to repeated restraint stress for 2-5 weeks show habituation of PA responses to the homotypic stressor, but increased ACTH and CORT responses to tail shock (Armario et al., 1988) or ether stress (Hashimoto et al., 1988). Prolonged and/or repeated exposure to isolation, crowding, or cold stress also results in habituation of $\mathrm{PA}$ responses to the homotypic stressor, but increased PA response to a novel stressor (Sakellaris and Vernikos-Dannellis, 1975; Vernikos et al., 1982). Together, these studies indicate that habituation of PA responses to chronic stressors is not due to a decrease in the responsivity of the $\mathrm{PA}$ axis per se, but to changes in the afferent control of hypothalamic paraventricular CRH neurons and/or other systems involved in the release of ACTH secretagogues. More specifically, habituation of PA responses to repeated stressor presentation might result from decreased activity of neuronal systems that positively influence this axis, increased activity of neuronal systems that negatively influence this axis, or a combination of such changes.

The present experiments were designed, therefore, to elucidate the neuroanatomical structures involved in PA responses to acute stress and habituation of these responses to repeated stress. For this purpose, the effects of acute and repeated restraint stress on neuronal activity were examined in brain regions that are known to regulate the PA-axis, including the cerebral cortex, hippocampus, hypothalamus, septum, amygdala, and brainstem. Changes in PA activity were determined by measuring plasma CORT levels following termination of the stressor. Changes in neuronal activity were examined by measuring levels of $\mathrm{c}$-fos mRNA in specific brain regions using Northern and slot blot techniques. A plethora of studies have established that the expression of this immediate early gene is rapidly induced by stimuli that increase neuronal activity (cf. Dragunow et al., 1989; Sheng and Greenberg, 1990; Morgan and Curran, 1991). However, it should be noted that exceptions to this general rule have also been found (Sagar et al., 1988; Jorgenson et al., 1989). Important for the present experiments is the fact that c-fos mRNA and protein are rapidly induced in structures previously shown to be activated metabolically using 2-deoxyglucose uptake or electrophysiological techniques by a variety of stressors including hypertonic saline (Ceccatelli et al., 1989; Giovanelli et al., 1990; Sharp et al., 1991), immobilization (Ceccatelli et al., 1989), foot shock (Campeau et al., 1991), conditioned avoidance learning (Anokhin and Ryabinin, 1989; Maleeva et al., 1989), tail shock (Schreiber et al., 1991), and water deprivation (Sagar et al., 1988).

\section{Materials and Methods}

Animals. Male Wistar rats (Charles River) weighing between 160 and $180 \mathrm{gm}$ at the start of each experiment were used. They were pair housed in Plexiglas cages $(45 \times 22 \times 20 \mathrm{~cm})$ with sawdust bedding and wcrc maintained at $22 \pm 0.4^{\circ} \mathrm{C}$ on a $12: 12 \mathrm{hr}$ light/dark schedule (lights on at 6:00 A.M.) with food and water continuously available except during stress sessions. Unless otherwise noted, all animals were handled daily for 1 week prior to experimentation.

Stress procedures. Rats were individually restrained for $2 \mathrm{hr}$ sessions in hemicylindrical $(20.5 \times 9 \times 6 \mathrm{~cm})$, well-ventilated, Plexiglas tubes. The tubes were just large enough to allow rats of the size used to turn around easily. The swim stress procedure consisted of placing animals in plastic cylindrical utility containers (base diameter $=26 \mathrm{~cm}$, top diameter $=29 \mathrm{~cm}$, height $=34 \mathrm{~cm}$ ) filled with $15 \mathrm{~cm}$ of $23^{\circ} \mathrm{C}$ water for 15 min. Animals were then lowel dried for $20 \mathrm{sec}$ and returned to their home cages.

Surgical procedures. Adrenalectomy was performed under halothane anesthesia using sterile conditions. Approximately $3 \mathrm{~cm}$ incisions were made on each side of the rat, the adrenal glands were removed with forceps, and incisions were closed with stainless steel wound clips. Shamoperated animals were treated identically except the adrenal glands were not removed. Both groups of animals were given continuous access to water and $0.9 \%$ saline throughout the remainder of the experiment.

General experimental procedures. The experimental designs for each experiment are described below in the Results section. In every experiment, animals were sacrificed by decapitation immcdiately following their last stress session (control animals were sacrificed at the same time as stressed animals). Brains were removed and cortex, hippocampus, hypothalamus, septum, amygdala, and brainstem were block dissected and stored at $-70^{\circ} \mathrm{C}$ prior to RNA isolation and Northern and slot blot analyses. For the last experiment, only cortex, hippocampus, and hypothalamus were taken. Trunk blood was always collected for determination of CORT levels.

Corticosterone assay. Immediately following decapitation, trunk blood was collected in chilled $1.5 \mathrm{ml}$ Eppendorf tubes containing $2.5 \mu \mathrm{l}$ of EDTA $(50 \mu \mathrm{g} / \mu \mathrm{l})$ and $2.5 \mu \mathrm{l}$ of aprotinin $(125,000 \mathrm{KUI} / \mathrm{ml})$. Samples were centrifuged and the supernatant was removed and frozen at $-70^{\circ} \mathrm{C}$. Ten microliters of plasma were used for determination of CORT levels by radioimmunoassay (ICN Biomedical). The intra- and interassay variability was less than $10 \%$.

RNA isolation, blotting, and hybridization analysis. Total RNA was isolated from dissections of selected brain regions of individual animals using the guanidinium-thiocyanate/acid phenol-chloroform extraction method of Chomczynski and Sacchi (1987). RNA was dissolved in sterile water, quantified by spectophotometry at $260 \mathrm{~nm}$ and stored at $-70^{\circ} \mathrm{C}$. For Northern blotting of cortex RNA, $20 \mu \mathrm{g}$ samples of RNA isolated from individual animals were denatured in $50 \% \mathrm{v} / \mathrm{v}$ formamide, $1.1 \mathrm{M}$ formaldehyde, $10 \mu \mathrm{g} / \mu \mathrm{l}$ ethidium bromide, and MOPS buffer $(\mathrm{pH}$ $=7.0$ ) (Sambrook et al., 1989) at $65^{\circ} \mathrm{C}$ and electrophoresed on an 0.8 M formaldehyde $1 \%$ agarose gel for $4 \mathrm{hr}$ in $1.1 \mathrm{M}$ formaldehyde/MOPS buffer. RNA was transferred to a Nytran nylon membrane (Schleicher $\&$ Schuell) via capillary action and cross-linked using a GS-Gene Linker (Bio-Rad). Integrity and loading of RNA were checked by ethidium bromide staining of ribosomal RNA. For slot blots performed in experiments one and two duplicate samples ( 2 and $4 \mu \mathrm{g}$ ) of RNA were denatured in $400 \mu \mathrm{l}$ of $50 \%$ formamide $(\mathrm{v} / \mathrm{v}), 10 \times \mathrm{SSC}$ for $10 \mathrm{~min}$ at $65^{\circ} \mathrm{C}$ and loaded onto nylon membranes using a Schleicher \& Schuell Manifold II slot blot system, washed with $10 \times$ SSC, and UV crosslinked. Because of the large number of animals used in experiment three, only a single RNA sample per animal $(10 \mu \mathrm{g})$ was slot blotted. RNA from different brain regions was loaded onto separate filters and on each filter a ladder of increasing concentrations of cortex RNA was added.

cDNA probes for c-fos (gift from T. Curran, Roche Institute), cyclophillin (gift from P. E. Danielson, The Scripps Research Institute), zif268, c-jun, jun-B, and jun-D (ATCC) were labeled with ${ }^{32}$ P-dCTP and ${ }^{32}$ P-dATP (Amersham) using the Decaprime kit from Ambion. Northern and slot filters were prehybridized for $12 \mathrm{hr}$ at $42^{\circ} \mathrm{C}$ in hybridization buffer containing $50 \%(\mathrm{v} / \mathrm{v})$ formamide, $2 \times$ Denhardt's, $0.5 \% \mathrm{SDS}, 1$ mM sodium pyrophosphate, $200 \mu \mathrm{g} / \mu$ l denatured salmon sperm DNA, and $200 \mu \mathrm{g} / \mu \mathrm{l}$ denatured yeast tRNA, and then hybridized overnight in the same buffer containing $2 \mathrm{ng} / \mathrm{ml}$ of labeled probe. Filters were washed in $0.5 \times$ SSC, $0.1 \%$ SDS, 1 mM sodium pyrophosphate for 30 min each at $37^{\circ} \mathrm{C}, 56^{\circ} \mathrm{C}$, and $65^{\circ} \mathrm{C}$, air dried, and autoradiographed using Amersham Hyperfilm-MP x-ray film. Exposure time depended upon signal strength and was kept within the linear range of the film by monitoring the linearity of the RNA ladder's signal. Most filters were. rehybridized several times with different probes following boiling in $0.1 \times$ SSC, $0.1 \%$ SDS.

Data quantification and statistical analysis. Band intensities were quantified by scanning autoradiograms into an Apple Macintosh II FX computer using a Microtek Scanmaker 600ZS scanner and Microtek 


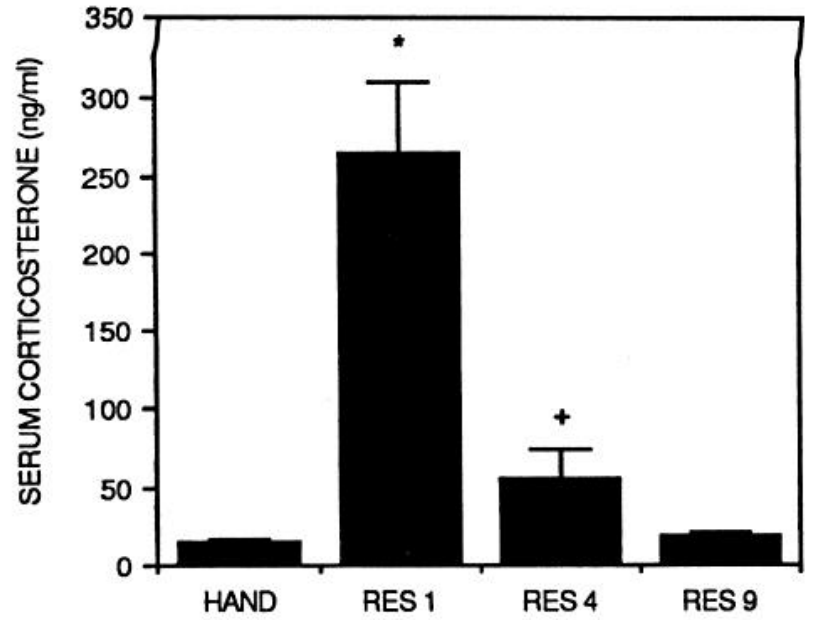

Figure 1. Mean serum corticosterone levels in handled controls and animals exposed to one, four, or nine daily $2 \mathrm{hr}$ restraint sessions. $H A N D$, handled control animals; RES 1 , animals after one $2 \mathrm{hr}$ restraint session; RES 4, animals after four daily $2 \mathrm{hr}$ restraint sessions; $R E S 9$, animals after nine $2 \mathrm{hr}$ restraint sessions. ${ }^{*}$, significantly different from all other groups; + , significantly different from RES 9.

BLACK AND WHITE software. Signal intensity was measured in pixels/ band using IMAGE 1.43 software (provided by Dr. W. Rasband, NIH). In each experiment c-fos data were normalized relative to corresponding cyclophillin values (for experiments 1 and 2 the average of the two concentrations of each sample was then calculated). Normalized data were statistically analyzed using one-way (experiments 1 and 2) and 2 $\times 2$ factorial (experiment 3 ) analysis of variance (ANOVA). Post hoc comparisons were made using the Fisher PLSD; $p$ values of less than 0.05 were considered statistically significant. Because hybridization parameters differed between slot blots, comparisons between groups should only be made within a particular brain region and experiment. Since not every sample from each brain region was analyzed, the number of samples used for statistical analyses do not necessarily correspond to the number of animals used in a particular experiment (see Tables 1$3)$.

\section{Results}

Effect of acute and repeated restraint stress on serum CORT levels and CNS c-fos expression (experiment 1)

To evaluate the effects of acute and repeated stress on PA and neuronal metabolic activation, serum CORT and CNS c-fos mRNA levels were analyzed in acutely stressed animals sacrificed immediately following a single $2 \mathrm{hr}$ restraint stress session (RES 1), and in repeatedly stressed animals sacrificed immediately following their fourth (RES 4) or ninth (RES 9) daily 2 $\mathrm{hr}$ restraint stress session (six animals/group). In addition, animals from a handled, nonstressed control group (HAND) were sacrificed on each of these days to control for possible effects of extraneous stressors (i.e., shared environmental stressors) on either dependent variable.

Consistent with other reports (Armario et al., 1988; Hashimoto et al., 1988; Natelson et al., 1988; De Boer et al., 1990; Hauger et al., 1990), acute stress markedly increased plasma levels of CORT in the present experiment, an effect that showed substantial habituation following repeated stressor presentation. Thus, a one-way ANOVA performed on the CORT values revealed a significant group effect $[F(3,20)=25.9 ; p=0.0001]$ and post hoc analyses indicated that CORT levels were significantly higher in acutely restrained animals relative to nonstressed controls and animals restrained once daily for either 4

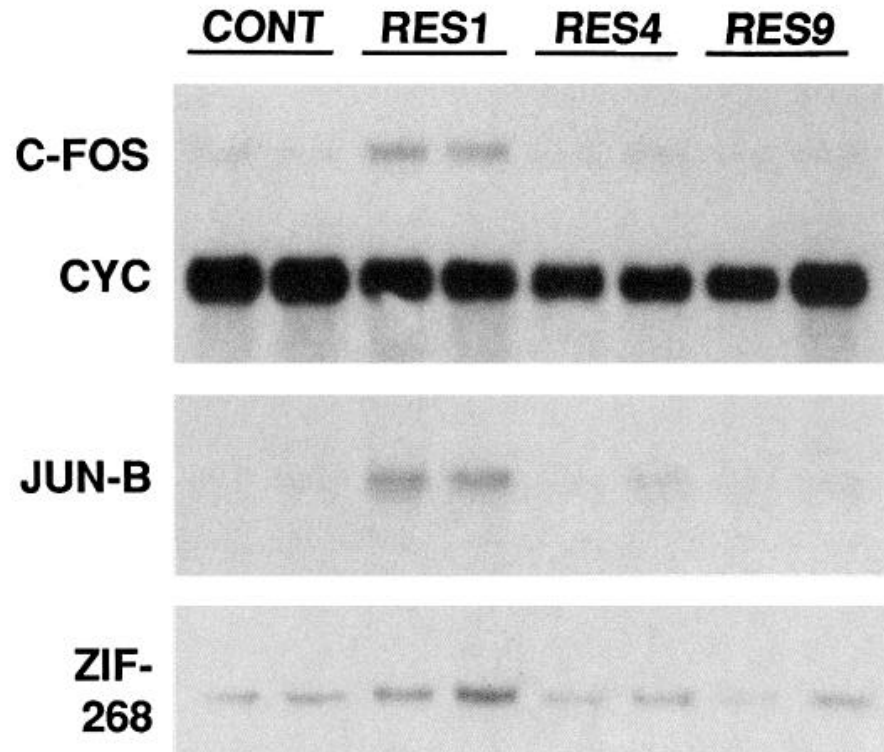

c-JUN

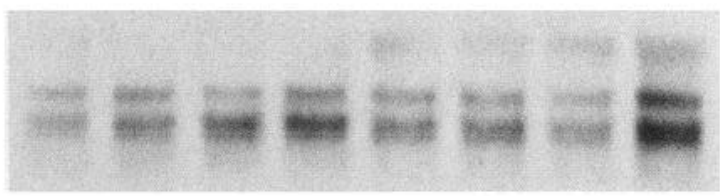

JUN-D

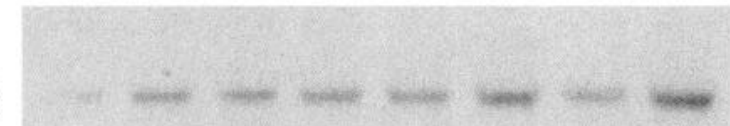

Figure 2. Northern blot of cortex RNA from handled controls and animals exposed to one, four, or nine daily $2 \mathrm{hr}$ restraint sessions (two/ group) sequentially hybridized with probes for c-fos and cyclophillin, jun-B, zif-268, c-jun, and jun-D. CONT, handled control animals; $R E S$ 1 , animals after one $2 \mathrm{hr}$ restraint session; $R E S 4$, animals after four 2 hr restraint sessions; $R E S 9$, animals after nine daily restraint sessions.

or $9 \mathrm{~d}$. Habituation was gradual but complete by the ninth session: plasma CORT levels in animals restrained for $4 \mathrm{~d}$ were not as high as those in acutely restrained rats, but were significantly higher than those in both nonstressed and animals restrained daily for $9 \mathrm{~d}$, which were not significantly different from each other (Fig. 1).

Northern blot analyses of cortex RNA obtained from nonstressed rats, as well as acutely and repeatedly stressed animals (two animals/group) were conducted first to examine the effect of these treatments on the expression of c-fos and other immediate early genes associated with altered neuronal activity including jun-B, c-jun, jun-D, and zif-268. Levels of c-fos and jun-B mRNA were markedly increased by acute restraint stress (Fig. 2). In contrast, levels of zif-268, c-jun, and jun-D were affected only marginally by acute stress. Exposure to repeated restraint stress led to habituation of c-fos, jun-B, and zif-268, but not c-jun and jun-D responses. The much stronger responsivity of c-fos and jun-B expression in cortex to acute stress was confirmed by slot blot hybridization analysis showing significant induction of c-fos $[+97 \% ; F(1,10)=32.7 ; p=0.0002]$ and jun-B $[+94 \% ; F(1,10)=60.1 ; p=0.0001]$, but not zif-268 $[+6 \%$; $F(1,10)=0.88 ; p=0.37]$, c-jun $[+17 \% ; F(1,10)=1.11 ; p=$ 
A.

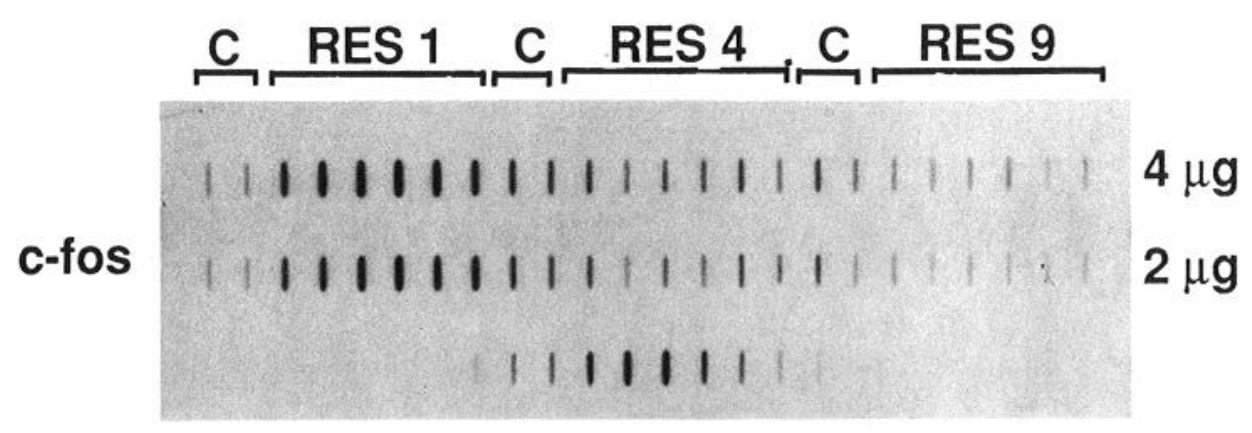

B.

Cyclophilin

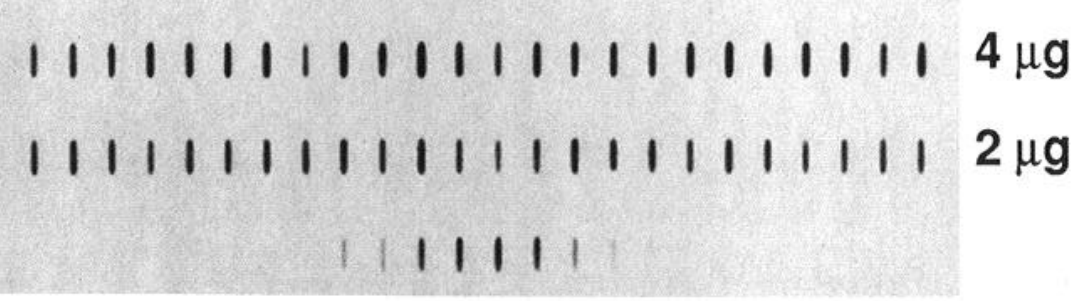

Figure 3. Slot blot of cortex RNA from handled controls $(C)$ and animals exposed to one, four or nine daily 2 hr restraint sessions sequentially hybridized with probes for c-fos and cyclophillin. $C$, handled control animals; RES1, animals after one 2 hr restraint session; RES4, animals after four daily $2 \mathrm{hr}$ restraint sessions; $R E S 9$, animals after nine $2 \mathrm{hr}$ restraint sessions.

$0.32]$, and jun-D $[0 \% ; F(1,10)=0.002 ; p=0.97]$ expression in acutely stressed animals $(n=6)$ when compared to handled controls $(n=6)$.

To examine the degree and anatomical pattern of stress-induced changes in neuronal metabolic activation, levels of c-fos mRNA were measured, by slot blot hybridization, in several brain regions known to influence the activity of the PA-axis. We focused on c-fos, even though cortical levels of jun-B and zif-268 mRNA were also regulated by restraint stress, because the relationship between neuronal activity and this particular gene has been most extensively characterized (cf. Dragunow et al., 1989; Sheng et al., 1990; Morgan and Curran, 1991). The magnitude and consistency of the data obtained in these experiments can be seen in Figure 3.

Figure 4 and Table 1 show the effects of acute and repeated restraint stress on expression of c-fos mRNA, determined by densitometric measurement of slot blot hybridization signals, in a number of brain regions. Levels of c-fos mRNA were generally increased by acute exposure to $2 \mathrm{hr}$ restraint stress, a response that habituated, at varying rates and to varying degrees in different brain regions, when animals were repeatedly stressed.

A one-way ANOVA performed on these data revealed a significant effect of stress on c-fos mRNA levels in almost every brain region examined including cortex $[F(3,20)=36 ; p=$ $0.0001]$, hippocampus $[F(3,20)=31.1 ; p=0.0001]$, hypothalamus $[F(3,18)=27.3 ; p=0.0001]$, septum $[F(3,18)=8.2 ; p=$ $0.001]$, and brainstem $[F(3,18)=3.3 ; p<0.05]$. A marginally significant effect was found in amygdala $[F(3,17)=3.01 ; p<$ 0.06]. Post hoc analysis of the data derived from the cortex slot blot indicated that levels of c-fos mRNA were significantly high- er in acutely restrained animals relative to nonstressed and repeatedly restrained ( 4 and $9 \mathrm{~d}$ ) animals. This response was completely habituated by the fourth restraint stress session: levels of c-fos mRNA in these animals were not significantly different from those in nonstressed controls but were higher than those in animals restrained daily for $9 \mathrm{~d}$. Highly similar patterns of c-fos induction and habituation were revealed when post hoc tests were performed on hypothalamic, septum, and brainstem data (see Table 1 for details). Hippocampal levels of c-fos mRNA were also significantly increased in acutely restrained rats relative to levels in controls and repeatedly restrained animals. However, habituation to repeated restraint stress appeared more gradual in this region than in the cortex, hypothalamus, septum, or brainstem; that is, levels of c-fos mRNA were still significantly increased in the hippocampus of animals restrained daily for $4 \mathrm{~d}$ relative to levels in controls and animals restrained daily for $9 \mathrm{~d}$. Although apparently increased (Fig. 4), levels of c-fos mRNA in the amygdala of acutely restrained animals were not statistically different from those in nonstressed controls or animals restrained daily for $4 \mathrm{~d}$ because of the high variability of the data. However, they were significantly higher than c-fos mRNA levels in animals restrained daily for $9 \mathrm{~d}$, presumably because this treatment produced a small but nonsignificant decrease in levels of this transcript in this region. Interestingly, levels of c-fos mRNA in animals restrained daily for $9 \mathrm{~d}$ were also decreased relative to control levels in cortex and septum. It should be noted that such inhibition was not particularly robust, nor was it seen in subsequent experiments (see below and Table 2). Its expression may depend upon the completeness of habituation. 


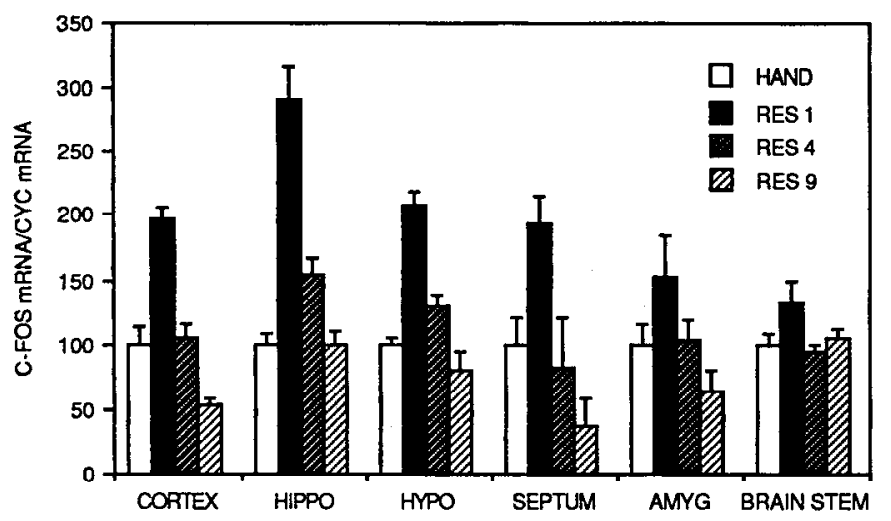

Figure 4. Mean levels of c-fos mRNA (normalized relative to cyclophillin and expressed as percentage of handled controls) in brain structures of handled controls and animals exposed to one, four, or nine daily $2 \mathrm{hr}$ restraint sessions. HAND, handled control animals; RES 1 , animals after one $2 \mathrm{hr}$ restraint session; $R E S 4$, animals after four daily $2 \mathrm{hr}$ restraint sessions; $R E S 9$, animals after nine daily $2 \mathrm{hr}$ restraint sessions.

Effect of repeated restraint stress on the ability of a novel stressor to increase serum CORT levels and CNS expression of c-fos $m R N A$ (experiment 2)

To determine whether the habituation of PA and CNS c-fos responses to repeated restraint stress observed in the previous experiment was specific, or the result of nonspecific perceptual, physiological, or molecular adaptations, we examined the effect of a novel stressor on these variables in rats adapted to restraint stress. Five groups of six animals were used: a control group that was completely naive (NAIVE), a group that was handled daily throughout the experiment (HAND), a group of repeatedly stressed rats that were sacrificed immediately following their ninth daily $2 \mathrm{hr}$ restraint session (RES 9), an acute stress group that was handled daily and then sacrificed $100 \mathrm{~min}$ following 20 min swim stress on day 9 (HAND/SW), and a restraint stress adapted/acute stress group that was restrained $2 \mathrm{hr} / \mathrm{day}$ for $8 \mathrm{~d}$ and sacrificed $100 \mathrm{~min}$ following $20 \mathrm{~min}$ swim stress on day 9 (RES/SW). These procedures were staggered so that all animals were sacrificed by decapitation on the same day.

Due to the brevity of the acute stressor $(20 \mathrm{~min})$ and the relatively long interval between stressor termination and decapitation (100 min), plasma levels of CORT were low at the time of sacrifice in all experimental groups, consistent with previous observations (Noda et al., 1991), and significant group differences were not observed.

In contrast, substantial and virtually identical effects of acute swim stress on CNS expression of c-fos mRNA were observed in both control (handled) and restraint stress-habituated animals (Table 2). This result clearly demonstrates that habituation of c-fos responses to repeated restraint stress is, in fact, stressor specific. Significant group differences in levels of c-fos mRNA were observed in every brain region examined including cortex $[F(4,17)=14.1 ; p=0.0001]$, hippocampus $[F(4,23)=7.2 ; p=$ $0.0006]$, hypothalamus $[F(4,22)=16.3 ; p=0.0001]$, septum $[F(4,24)=8.3 ; p=0.0002]$, amygdala $[F(4,23)=23.5 ; p=$ $0.0001]$, and brainstem $[F(4,22)=5.6 ; p=0.003]$. Post hoc analyses of the cortex data revealed that, relative to stress-naive animals, c-fos mRNA levels were not significantly altered by daily handling, the control treatment used in the previous experiment. Moreover, c-fos mRNA levels in animals exposed to nine daily restraint sessions were not significantly different from nonstressed control levels (naive or handled), indicating complete habituation of the effect of restraint stress on the expression of this gene. In contrast, acute swim stress significantly increased levels of c-fos mRNA in both handled and restraint-adapted animals relative to levels in naive, handled, and restraint-habituated animals. Identical patterns of c-fos induction were found in hippocampus, septum, and amygdala. A similar induction pattern was seen in the hypothalamus except that the level of c-fos mRNA in animals exposed to restraint stress daily for 9 d was significantly higher than that in naive but not handled nonstressed controls, and in the brainstem with the exception that levels of c-fos mRNA in repeatedly restrained animals exposed to swim stress were significantly higher than those in handled and repeatedly restrained animals but was not greater than those in naive controls (see Table 2).

\section{Effect of adrenalectomy on activation and habituation of serum CORT levels and CNS expression of c-fos $m R N A$ by acute and repeated restraint stress (experiment 3 )}

To ascertain whether the activation and habituation of c-fos mRNA responses to stress are secondary to changes in plasma levels of CORT, the effect of adrenalectomy on c-fos responses to acute and repeated restraint stress was examined. A total of nine groups of animals were used in this experiment: three groups each of unoperated (UN-OP), sham adrenalectomized (SHAM), and adrenalectomized (ADX) animals were sacrificed either (1) without ever being restrained (HAND), (2) immediately following a single $2 \mathrm{hr}$ restraint session (RES 1), or (3) immediately following the ninth $2 \mathrm{hr}$ restraint session (RES 9). Experimental manipulations commenced $8 \mathrm{~d}$ following surgery. One half of the three nonstressed control groups were sacrificed on the same day as acutely stressed animals while the remaining controls were sacrificed with the repeatedly restrained animals.

Consistent with results obtained in experiment one, acute restraint stress markedly increased plasma levels of CORT in both unoperated and sham-operated animals and this response was markedly habituated in animals exposed to nine daily restraint stress sessions (Fig. 5). Adrenalectomy reduced basal CORT to barely detectable levels and completely blocked its induction by acute restraint stress. Statistical analysis of these data (two-way factorial ANOVA) revealed significant effects of stress $[F(2,39)=81.7 ; p=0.0001]$ and surgery $[F(2,39)=70.6$; $p<0.0001]$, and a significant stress by surgery interaction $[F(4,39)=25.1 ; p=0.0001]$, reflecting this differential effect of stress on adrenalectomized rats relative to unoperated and shamoperated controls. Post hoc analyses confirmed that acute restraint stress significantly increased CORT levels in unoperated and sham, but not in adrenalectomized animals relative to nonstressed and repeatedly stressed, unoperated, sham, and adrenalectomized animals. There was no statistical difference between CORT levels of unoperated, sham, and adrenalectomized animals that were either not stressed or repeatedly stressed.

In contrast to its effects on basal and stress-induced changes in circulating levels of glucocorticoids, adrenalectomy did not alter basal levels of c-fos mRNA, the ability of acute stress to increase c-fos expression, or habituation of this induction following repeated stressor presentation in cortex, hippocampus, or hypothalamus (Table 3). Statistical analyses of densitometric measurements of cortex slot blot hybridization signals (two-way ANOVA) revealed a significant effect of stress $[F(2,37)=10.4$; $p=0.0003]$, but not a significant effect of surgery $[F(2,37)=$ $0.71 ; p=0.5]$ or stress by surgery interaction $[F(4,37)=1.1 ; p$ 
Table 1. Relative c-fos mRNA levels in brain of acutely and repeatedly restraint-stressed rats

\begin{tabular}{|c|c|c|c|c|c|c|}
\hline Group & Cortex & Hippo & Hypo & Septum & Amyg & Brainstem \\
\hline HAND & $\begin{array}{l}0.39 \pm 0.06 \\
(6)\end{array}$ & $\begin{array}{l}0.20 \pm 0.02 \\
(6)\end{array}$ & $\begin{array}{l}0.32 \pm 0.01 \\
(5)\end{array}$ & $\begin{array}{l}0.92 \pm 0.19 \\
(6)\end{array}$ & $\begin{array}{l}0.38 \pm 0.06 \\
(6)\end{array}$ & $\begin{array}{l}1.1 \pm 0.09 \\
(5)\end{array}$ \\
\hline RES 1 & $\begin{array}{l}0.77 \pm 0.04^{*} \\
(6)\end{array}$ & $\begin{array}{l}0.57 \pm 0.05^{*} \\
(6)\end{array}$ & $\begin{array}{l}0.67 \pm 0.03^{*} \\
(5)\end{array}$ & $\begin{array}{l}1.8 \pm 0.35^{*} \\
(4)\end{array}$ & $\begin{array}{l}0.58 \pm 0.12 \dagger \\
(5)\end{array}$ & $\begin{array}{l}1.5 \pm 0.18^{*} \\
(5)\end{array}$ \\
\hline RES 4 & $\begin{array}{l}0.41 \pm 0.04 \dagger \\
(6)\end{array}$ & $\begin{array}{l}0.30 \pm 0.03 \dagger \\
(6)\end{array}$ & $\begin{array}{l}0.41 \pm 0.03 \dagger \\
(6)\end{array}$ & $\begin{array}{l}0.75 \pm 0.18 \\
(6)\end{array}$ & $\begin{array}{l}0.39 \pm 0.06 \\
(5)\end{array}$ & $\begin{array}{l}1.1 \pm 0.08 \\
(6)\end{array}$ \\
\hline RES 9 & $\begin{array}{l}0.21 \pm 0.02 \ddagger \\
(6)\end{array}$ & $\begin{array}{l}0.19 \pm 0.02 \\
(6)\end{array}$ & $\begin{array}{l}0.26 \pm 0.04 \\
(6)\end{array}$ & $\begin{array}{l}0.35 \pm 0.04 \ddagger \\
(6)\end{array}$ & $\begin{array}{l}0.24 \pm 0.06 \\
(5)\end{array}$ & $\begin{array}{l}1.2 \pm 0.07 \\
(6)\end{array}$ \\
\hline
\end{tabular}

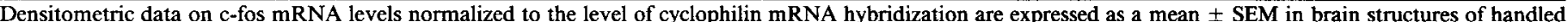

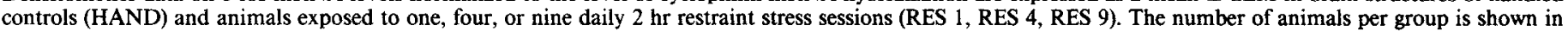
parentheses.

* Significantly different from all other groups.

$\uparrow$ Significantly different from RES 9.

$\ddagger$ Significantly different from handled controls.

$=0.4]$, supporting this interpretation. Statistical analyses of data obtained from hippocampal and hypothalamic slot blot hybridizations revealed identical patterns of results: a two-way ANOVA performed on hippocampus data revealed a significant stress effect $[F(2,39)=11.9 ; p=0.0001]$, but not surgery $[F(2,39)$ $=0.6 ; p=0.6]$ or stress by surgery interaction $[F(4,39)=0.8$; $p=0.6]$, and a two-way ANOVA performed on hypothalamic data revealed a significant effect of stress $[F(2,38)=23.3 ; p=$ $0.0001]$, but not a significant effect of surgery $[F(2,38)=1.6 ; p$ $=0.2]$ or stress by surgery interaction $[F(4,38)=1.1 ; p=0.4]$. Post hoc analyses of cortical, hippocampal and hypothalamic data revealed a significant effect of acute restraint stress on c-fos mRNA in unoperated, sham, and adrenalectomized animals relative to nonstressed controls in each of these regions. Levels of c-fos mRNA in unoperated, sham, and adrenalectomized animals exposed to repeated restraint stress were not significantly different from their respective nonstressed or acutely stressed counterparts indicating partial habituation of this response (see Table 3).

\section{Discussion}

To begin to identify the central systems underlying habituation of the PA-axis to repeated stress, we examined the expression of c-fos mRNA, as an indicator of altered neuronal activity (cf. Morgan and Curran, 1991), in brain regions known to influence basal and stress-induced activity of this axis including the cortex, hippocampus, hypothalamus, septum, amygdala, and brainstem. Lesion and electrical stimulation studies have indicated that certain brainstem (Szafarczyk et al., 1985; Sawchenko, 1991) and hypothalamic (Dohanics et al., 1986; Richardson-Morton et al., 1989) nuclei positivcly influcnce basal and stress-induced activity of the PA-axis. In contrast, specific cortical regions, hippocampus, and the lateral septal area are involved in inhibitory regulation of this axis (Seggie et al., 1973; Sapolsky et al., 1984; Saphier and Feldman, 1987; Herman et al., 1990). The role of the amygdala in PA function is more complicated with some studies suggesting facilitation (Mason, 1959; Beaulieu et al., 1986; Dunn and Whitener, 1986) and others inhibition (cf. Allen and Allen, 1975; Dunn and Whitener, 1986) of basal and evoked PA activity by this structure. Based on this literature, one hypothesis might be that acute stress could lead to increased neuronal activity, and hence c-fos expression, in stimulatory but not inhibitory PA afferents, while repeated stress would primarily increase neuronal activity in inhibitory PA afferents. Contrary to this expectation our data show decreased c-fos ex-

Table 2. Relative c-fos mRNA levels in brain after exposure to a novel (swim) stress

\begin{tabular}{|c|c|c|c|c|c|c|}
\hline Group & Cortex & Hippo & Hypo & Septum & Amyg & Brainstem \\
\hline NAIVE & $\begin{array}{l}0.30 \pm 0.01 \\
(5)\end{array}$ & $\begin{array}{l}0.34 \pm 0.05 \\
(6)\end{array}$ & $\begin{array}{l}0.18 \pm 0.02 \\
(5)\end{array}$ & $\begin{array}{l}0.09 \pm 0.04 \\
(5)\end{array}$ & $\begin{array}{l}0.37 \pm 0.08 \\
(6)\end{array}$ & $\begin{array}{l}0.36 \pm 0.09 \\
(5)\end{array}$ \\
\hline HAND & $\begin{array}{l}0.32 \pm 0.14 \\
(4)\end{array}$ & $\begin{array}{l}0.29 \pm 0.002 \\
(6)\end{array}$ & $\begin{array}{l}0.27 \pm 0.03 \\
(4)\end{array}$ & $\begin{array}{l}0.17 \pm 0.03 \\
(6)\end{array}$ & $\begin{array}{l}0.29 \pm 0.04 \\
(5)\end{array}$ & $\begin{array}{l}0.34 \pm 0.05 \\
(6)\end{array}$ \\
\hline RES 9 & $\begin{array}{l}0.32 \pm 0.06 \\
(5)\end{array}$ & $\begin{array}{l}0.31 \pm 0.04 \\
(6)\end{array}$ & $\begin{array}{l}0.28 \pm 0.02 \dagger \\
(6)\end{array}$ & $\begin{array}{l}0.25 \pm 0.07 \\
(6)\end{array}$ & $\begin{array}{l}0.17 \pm 0.03 \\
(6)\end{array}$ & $\begin{array}{l}0.31 \pm 0.02 \\
(5)\end{array}$ \\
\hline $\mathrm{H} / \mathrm{SW}$ & $\begin{array}{l}1.5 \pm 0.20^{*} \\
(4)\end{array}$ & $\begin{array}{l}0.64 \pm 0.10^{*} \\
(4)\end{array}$ & $\begin{array}{l}0.68 \pm 0.05^{*} \\
(5)\end{array}$ & $\begin{array}{l}0.58 \pm 0.14^{*} \\
(6)\end{array}$ & $\begin{array}{l}0.86 \pm 0.06^{*} \\
(6)\end{array}$ & $\begin{array}{l}0.63 \pm 0.05^{*} \\
(5)\end{array}$ \\
\hline RES/SW & $\begin{array}{l}1.2 \pm 0.22^{*} \\
(4)\end{array}$ & $\begin{array}{l}0.66 \pm 0.09^{*} \\
(6)\end{array}$ & $\begin{array}{l}0.73 \pm 0.03^{*} \\
(G)\end{array}$ & $\begin{array}{l}0.61 \pm 0.07^{*} \\
(6)\end{array}$ & $\begin{array}{l}0.71 \pm 0.08^{*} \\
(5)\end{array}$ & $\begin{array}{l}0.53 \pm 0.07 \ddagger \\
(6)\end{array}$ \\
\hline
\end{tabular}

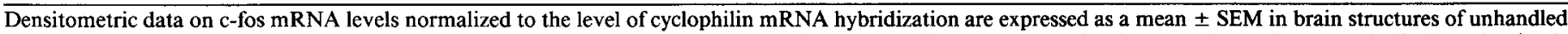

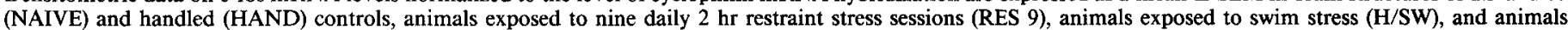
exposed to swim stress after eight daily restraint sessions (RES/SW). The number of animals per group is shown in parentheses.

* Significantly different from NAIVE, HAND, RES 9.

$\dagger$ Significantly different from NAIVE.

$\$$ Significantly different from HAND, RES 9 . 


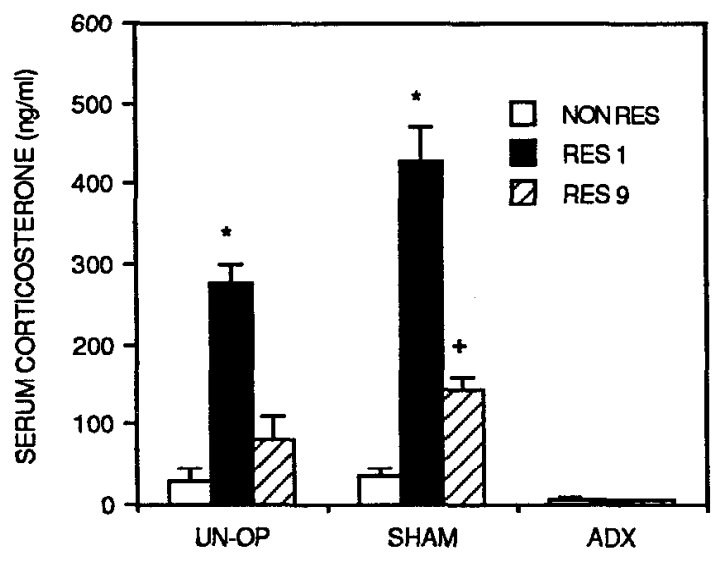

Figure 5. Mean serum corticosterone levels in unoperated, sham-operated, and adrenalectomized rats not restrained or exposed to one or nine daily $2 \mathrm{hr}$ restraint sessions. $U N-O P$, unoperated animals; $S H A M$, sham-operated animals; $A D X$, adrenalectomized animals; NON RES, handled control animals; RES 1 , animals exposed to one $2 \mathrm{hr}$ session of restraint stress; $R E S$, animals exposed to nine daily $2 \mathrm{hr}$ restraint sessions. *, significantly different from all other groups; +, significantly different from NON-RES/ADX, ADX/RES 1, ADX/RES 9.

pression after repeated stress through all brain regions tested, including cortex, hippocampus, and septum.

The effects of acute restraint stress on c-fos mRNA levels in these discrete brain regions were consistent with the existing literature (Ceccatelli et al., 1989; Imaki et al., 1992; Covenas et al., 1993; Stone et al., 1993). Acute restraint stress lead to significantly increased expression of c-fos mRNA in the cortex, hippocampus, hypothalamus, and scptum. In contrast, acute restraint stress only marginally increased the level of c-fos mRNA in the brainstem; it is likely that larger effects of this stimulus in discrete brainstem nuclei may have been obscured by the gross nature of the dissection (Pezzone et al., 1993; Stone et al.,
1993). Acute restraint stress also produced a vcry small incrcase in c-fos expression in the amygdala. This is surprising given the critical role this complex plays in the regulation of behavioral, autonomic, and endocrine responses to stressful or fear-eliciting stimuli (cf. Davis, 1992). However, several groups have reported differential effects of stress on the induction of $\mathrm{c}$-fos and related fra (fos-related antigen) proteins within individual amygdaloid subnuclei (Arnold et al., 1992; Pezzone et al., 1992), and conflicting effects of stressful stimuli on amygdaloid levels of c-fos mRNA have also been reported (Campeau et al., 1991; Smith et al., 1992). Such variability can be partially explained by qualitative differences between the stressors and techniques employed in these studies, but the contribution of the heterogeneity of the amygdaloid complex to these various findings should also be considered.

Repeated exposure to restraint stress produced rapid habituation of c-fos responses to this stressor; by the fourth session restraint stress no longer increased c-fos expression above control levels in any region but hippocampus, and by the ninth session levels of c-fos mRNA in cortex, septum, and amygdala were actually lower than control levels. These results support the contention that PA habituation is mediated by decreased neuronal activity in facilitatory PA afferents and argue against the hypothesis that habituation is mediated by increased neuronal activity in inhibitory afferents. It is possible, however, that increased expression of c-fos mRNA did occur in circumscribed populations of cells within inhibitory structures but that this effect was obscured by the gross nature of the dissections. Further cellular resolution employing in situ hybridization or immunohistochemical analyses will be required to evaluate this hypothesis more fully. Because the present experiments are correlational the observed changes in c-fos mRNA expression in $\mathrm{PA}$ afferents in response to stress might not be directly related to changes in the activity of the PA-axis in response to stress. To address this issue more directly we are now planning to examine whether lesions of these afferents will modify habituation of PA responses to repeated stress.

$\begin{aligned} & \text { Table 3. Relative c-fos mRNA levels in brain of acutely and repeatedly restraint stressed rats after } \\
& \text { adrenalectomy }\end{aligned}$
\begin{tabular}{llll} 
Group & Cortex & Hippo & Hypo \\
\hline UN-OP & $0.71 \pm 0.32(4)$ & $0.34 \pm 0.04(4)$ & $1.5 \pm 0.10(4)$ \\
SHAM & $0.59 \pm 0.10(6)$ & $0.52 \pm 0.06(6)$ & $1.8 \pm 0.20(5)$ \\
ADX & $0.69 \pm 0.07(5)$ & $0.52 \pm 0.04(6)$ & $2.0 \pm 0.26(6)$ \\
UN-OP/RES 1 & $1.1 \pm 0.08(5) \ddagger$ & $0.77 \pm 0.12(6)^{a *}$ & $2.9 \pm 0.13(5)^{a *}$ \\
SHAM/RES 1 & $1.2 \pm 0.19(5)^{*}$ & $0.70 \pm 0.13(5)^{b \dagger}$ & $3.1 \pm 0.24(5)^{a *}$ \\
ADX/RES 1 & $1.1 \pm 0.14(6)^{*}$ & $0.71 \pm 0.04(5)^{a \dagger}$ & $3.0 \pm 0.16(6)^{b *}$ \\
UN-OP/RES 9 & $0.83 \pm 0.10(3)$ & $0.39 \pm 0.07(4)$ & $2.1 \pm 0.29(4)$ \\
SHAM/RES 9 & $0.90 \pm 0.10(6)$ & $0.48 \pm 0.05(6)$ & $2.4 \pm 0.25(6)$ \\
ADX/RES 9 & $0.50 \pm 0.09(6)$ & $0.42 \pm 0.09(6)$ & $1.8 \pm 0.24(6)$
\end{tabular}

Densitometric data on c-fos mRNA levels normalized to the levels of cyclophilin mRNA hybridization are expressed as a mean \pm SEM in brain structures of unoperated (UN-OP), sham-operated (SHAM), adrenalectomized (ADX) handled control animals, unoperated (UN-OP/RES 1), sham-operated (SHAM/RES 1), adrenalectomized (ADX/RES 1) animals exposed to a single $2 \mathrm{hr}$ restraint session, unoperated (UN-OP/RES 9), sham-operated (SHAM/RES 9), and adrenalectomized (ADX/RES 9) animals exposed to nine daily 2 hr restraint sessions. Number of animals per group is shown in parentheses.

${ }^{a}$ Significantly different from UN-OP/RES 9, SHAM/RES 9; ADX/RES 9.

"Significantly different from RES 9, ADX/RES 9.

* Significantly different from IN-OP, SHAM, ADX.

$\uparrow$ Significantly different from UN-OP.

$\ddagger$ Significantly different from SHAM, ADX. 
Winston et al. (1990) reported similar habituation of c-fos and c-jun expression in cortex of animals exposed to daily electroconvulsive shock (ECS) for $10 \mathrm{~d}$ : by day 5 the stimulus evoked $50 \%$ of the c-fos response effected by acute ECS, and by day 10 the stimulus no longer induced c-fos mRNA at all. Similarly, Hope et al. (1992) found that repeated daily cocaine resulted in complete habituation of immediate early gene responses to this stimulus by treatment day 15 . Both groups suggested that the decreased responsiveness of immediate early genes to repeated stimulus presentation might be due to a long-term form of autoinhibition (Sassone-Corsi et al., 1988) mediated by fos-related proteins, fra, which can remain elevated for up to $7 \mathrm{~d}$ following the presentation of a single stimulus (Sonnenberg et al., 1989; Sharp et al., 1991).

To address the possibility that habituation of central responses to repeated stressor presentation might result from autoinhibition or other nonspecific biological changes, we examined the ability of a novel stressor to induce c-fos mRNA in restraint-adapted rats. Acute swim stress produced virtually identical increases in the expression of c-fos mRNA in a number of brain regions in both controls and animals habituated to restraint stress. In both groups of rats the greatest c-fos responses were found in the septum, with smaller responses in the hypothalamus and cortex and yet smaller responses in the hippocampus, amygdala, and brainstem. This pattern of c-fos induction is very different from that produced by acute restraint stress, which caused the greatest induction of c-fos mRNA in the hippocampus, less in the cortex, hypothalamus, and septum and only very small increases in the amygdala and brainstem, supporting the hypothesis that different stressors activate different neural pathways (cf. Harbuz and Lightman, 1992). Together these data indicate that habituation of central responses to repeated stress are, like PA responses, stressor specific and not the result of autoinhibition or a blunted physiological response capacity.

The mechanism(s) underlying such "dishabituation" has been addressed by Hashimoto et al. (1988) and Hauger et al. (1988), who found that repeatedly restrained rats that showed PA habituation to a homotypic stressor, but increased ACTH and CORT responses to a novel stressor, exhibited normal or exaggerated PA responses to exogenous CRH and sensitized responses to exogenous vasopressin (see also Harbuz. and I ightman, 1992). These data, coupled with the observation that repeated stress increases the expression of vasopressin in the hypothalamic paraventricular nucleus and the internal lamina of the median eminence (De Goeij et al., 1991), suggest that a novel stressor may increase $P A$ activity in restraint-adapted rats via a sensitized vasopressinergic mechanism. In the experiments described here c-fos responses to stress were always examined $2 \mathrm{hr}$ after onset of stress. Since c-fos responses generally peak from 30 to $60 \mathrm{~min}$ following stimulus (Muller et al., 1984), facilitatory effects of restraint stress on c-fos expression in restraint habituated animals might have been missed. However, this possibility seems unlikely, since it would require repeated stress to lead to increased turnover of c-fos mRNA and that this change in rate of turnover would be stimulus specific.

Thus, the results of the present study suggest that different stressors result in dissimilar patterns of neuronal activation. Our observations support the supposition that novel stressors increase the activity of the PA-axis in stress-adapted animals by activating alternative neural pathways ultimately resulting in the release of distinct combinations of ACTH secretagogues (cf.
Harbuz and Lightman, 1992). An alternative interpretation of the present results is that stress-induced changes in CNS expression of $c$-fos mRNA are the consequence and not the cause of altered PA activity. However, in the present study, adrenalectomy virtually eliminated basal and stress-induced CORT, but did not alter basal expression of c-fos mRNA in cortex, hippocampus, or hypothalamus, or the induction and habituation of $\mathrm{c}$-fos responses following acute and repeated restraint stress. These findings conflict with the work of Jacobson et al. (1990), who reported that adrenalectomy increases fos-like immunoreactivity in $\mathrm{CRH}$ and vasopressin containing cells of the hypothalamic paraventricular nucleus 1,3 , and $7 \mathrm{~d}$ following surgery. However, a polyclonal antiserum was used in their study and it is likely that this antibody detected not only c-fos but also fos-related antigens, which can be elevated for up to a week following stimulus presentation (Sonnenberg et al., 1989; Sharp et al., 1991). Consistent with this interpretation, Brown and Sawchenko (1993) did not find elevated levels of c-fos in the paraventricular nucleus of hypothalamus a week after adrenalectomy using a specific for c-fos, N-terminally directed antisera.

Consistent with other studies (Kornhauser et al., 1992; Rosen et al., 1992), similar patterns of induction and habituation to acute and repeated restraint stress were seen in the cortex for $\mathrm{c}$-fos and jun-B but not $\mathrm{c}$-jun or jun-D mRNAs, suggesting that any transcriptional effects of c-fos induction may be mediated by dimerization of the c-Fos and Jun-B proteins. In contrast to the members of the fos-jun transcription factor family, zif-268 mRNA was not induced after acute restraint, probably reflecting a high basal level of zif- 268 expression in cortex described by others (Worley et al., 1991), but was, however, markedly decreased after exposure to repeated stressors, demonstrating that expression of this gene is also a subject to habituation.

In summary, we have found that acute and repeated stress regulates $\mathrm{PA}$ activity and neuronal responses in brain regions known to influence the activity of the PA-axis in a parallel fashion: acute stress increases plasma CORT and c-fos mRNA levels in specific brain regions while repeated restraint stress produces marked habituation of both these responses. The pattern of neuronal responses to acute stress and habituation to repeated stress is stressor specific and independent of circulating levels of adrenal steroids. Recent studies suggest that excitatory amino acids (Birder and de Groat, 1992; Morgan et al., 1992; cf. Morgan and Curran, 1991; Le et al., 1992) and norepinephrine (Gubits et al., 1989; Bing et al., 1991; Stone et al., 1993) contribute to the induction of $\mathrm{c}$-fos by acute stressors. A number of other substances have been shown to regulate expression of c-fos in vitro, including NGF, FGF, EGF, IL-6, and nicotinic agonists (cf. Morgan and Curran, 1991). Adaptation of c-fos responses to repeated stress could be due to changes in the concentrations of, receptors for, or signal transduction systems coupled with any combination of these factors.

The present data indicate that habituation is a perceptual event; restraint stress ceases to mobilize the PA-axis not because the capacity of the neural inputs to this axis is "exhausted," but because the meaning of the stressor for the animal has changed. If we can identify the neuroanatomical, biochemical, and molecular mechanisms underlying this adaptive phenomenon we may eventually be able to understand the physiological substrates of those psychiatric illnesses that can be characterized by a breakdown in inhibitory systems and/or hyperactivity of the PA-axis, including anxiety and obsessive compulsive dis- 
orders, and certain componcnts of bipolar and unipolar depression and schizophrenia (Holsboer et al., 1989; Smith et al., 1989; Johnson et al., 1992).

\section{References}

Allen JP, Allen CF (1975) Amygdalar participation in tonic ACTH secretion in the rat. Neuropharmacology 19:115-125.

Anokhin KV, Ryabinin AE (1989) c-fos gene expression in the mouse brain after active avoidance learning. Eur J Neurosci [Suppl] 4:62.

Armario A, Hidalgo J, Giralt M (1988) Evidence that the pituitaryadrenal axis does not cross adapt to stressors: comparison to other physiological variables. Neuroendocrinology 47:263-267.

Arnold FJ, De Lucas Bueno M, Shriers H, Hancock DC, Evan GI, Herbert J (1992) Expression of $c$-fos in regions of the basal limbic forebrain following intracerebroventricular corticotropin-releasing factor in unstressed or stressed male rats. Neuroscience 51:377-390.

Aserita MF (1985) The physiology of stress. New York: Human Sciences.

Beaulieu S, Pelletier G, Vaudry H, Barden N (1989) Influence of the central nucleus of the amygdala on the content of corticotropin-releasing factor in the median eminence. Neuroendocrinology 49:255261.

Bing G, Filer D, Miller JC, Stone EA (1991) Noradrenergic activation of immediate early genes in rat cerebral cortex. Mol Brain Res 11: $43-46$.

Birder LA, de Groat WC (1992) The effect of glutamate antagonists on c-fos expression induced in spinal neurons by irritation of the lower urinary tract. Brain Res 580:115-120.

Bresiau N, Davis GC (1986) Chronic stress and major depression. Arch Gen Psychiatry 43:309-314.

Brown ER, Sawchenko PE (1993) Adrenalectomy presents a dynamic stimulatory challenge to parvocellular neurosecretory neurons. Soc Neurosci Abstr 19:760.

Campeau S, Hayward M, Hope BT, Rosen JB, Nestler EJ, Davis M (1991) Induction of the c-fos proto-oncogene in rat amygdala during unconditioned and conditioned fear. Brain Res 565:349-352.

Cannon WB (1939) The wisdom of the body. New York: Norton.

Ceccatelli S, Villar MJ, Goldstein M, Hokfelt T (1989) Expression of c-fos immunoreactivity in transmitter-characterized neurons after stress. Proc Natl Acad Sci USA 86:9569-9573.

Chomczinski P, Sacchi N (1987) Single step method of RNA isolation by acid guanidinium thiocyanate-phenol-chloroform extraction. Anal Biochem 162:156-159.

Covenas R, de Leon M, Cintra A, Bjelke B, Gustafsson JA, Fuxe K (1993) Coexistence of $\mathrm{c}$-fos and glucocorticoid receptor immunoreactivities in the CRF immunoreactive neurons of the paraventricular hypothalamic nucleus of the rat after acute immobilization stress. Neurosci Lett 149:149-152.

Davis M (1992) The role of the amygdala in conditioned fear. In: The amygdala: neurobiological aspects of emotion, memory and mental dysfunction (Agleton J, ed). New York: Wiley.

De Boer SF, Koopman SJ, Slangen JL, Van Der Gugten J (1990) Plasma catecholamine, corticosterone and glucose responses to repeated stress in rats: effect of interstressor interval length. Physiol Behav 47:1117-1124.

De Goeij DCE, Kvetnansky R, Whitnall MH, Jezova D, Berkenbosch F, Tilders FJH (1991) Repeated stress-induced activation of corticotropin releasing factor neurons enhances vasopressin stores and colocalization with corticotropin-releasing factor in the median eminence of rats. Neuroendocrinology 53:150-159.

Dohanics J, Kapocs G, Janaky T, Kiss JZ, Rappay G, Laszlo FA, Makara GB (1986) Mechanism of restoration of ACTH release in rats with long term lesions of the paraventricular nuclei. Endocrinology 111: 75-82.

Dunn JD, Whitener J (1986) Plasma corticosterone responses to electrical stimulation of the amygdaloid complex: cytoarchitectural specificity. Neuroendocrinology 42:211-217.

Dragunow M, Currie RW, Faull RLM, Robertson HA, Jansen K (1989) Immediate early genes, kindling and long-term potentiation. Neurosci Biobehav Rev 13:301-313.

Giovannelli L, Shiromani PJ, Jirikowski GF, Bloom FE (1990) Oxytocin neurons in the rat hypothalamus exhibit c-fos immunoreactivity upon osmotic stress. Brain Res 531:299-303.

Gubits RM, Smith TM, Fairhurst JL, Yu H (1989) Adrenergic recep- tors mediate changes in c-fos mRNA levels in brain. Mol Brain Res 6:39-45.

Harbuz MS, Lightman SL (1992) Stress and the hypothalamo-pituitary-adrenal axis: acute, chronic and immunological activation. J Endocrinol 134:327-339.

Hashimoto K, Suemaru S, Takao T, Sugawara M, Makino S, Ota Z (1988) Corticotropin-releasing hormone and pituitary-adrenocortical responses in chronically stressed rats. Reg Pep 23:117-126.

Hauger RL, Millan MA, Lorang M, Harwood JP, Aguilera G (1988) Corticotropin-releasing factor receptors and pituitary adrenal responses during immobilization stress. Endocrinology 123:396-405.

Hauger RL, Lorang H, Irwin M, Aguilera G (1990) CRF receptor regulation and sensitization of ACTH responses to acute ether stress during chronic intermittent immobilization stress. Brain Res 532:34 40.

Herman JP, Wiegard SJ, Watson SJ (1990) Regulation of basal corticotropin-releasing hormone and arginine vasopressin messenger ribonucleic acid expression in the paraventricular nucleus: effects of selective hypothalamic deafferentations. Endocrinology 127:24082417.

Holsboer F (1989) Psychiatric implications of altered limbic-hypothalamic-pituitary-adrenocortical activity. Eur Arch Psychiat Neurol Sci 238:302-322.

Hope B, Kosofsky B, Hyman S, Nestler EJ (1992) Regulation of immediate early gene expression and AP-1 binding in the nucleus accumbens by chronic cocainc. Proc Natl Acad Sci USA 89:5764-5768.

Imaki T, Shibasaki T, Hotta M, Demura H (1992) Early induction of c-fos precedes increased expression of corticotropin releasing factor messenger ribonucleic acid in the paraventricular nucleus after immobilization stress. Endocrinology 131:240-246.

Jacobson L, Sharp FR, Dallman MF (1990) Induction of fos-like immunoreactivity in hypothalamic corticotropin releasing factor neurons after adrenalectomy in the rat. Endocrinology 126:1709-1720.

Johnson EO, Kamilaris TC, Chrousos GP, Gold PW (1992) Mechanisms of stress: a dynamic overview of hormonal and behavioral homeostasis. Neurosci Biobehav Rev 16:115-130.

Jorgenson M, Deckert J, Wright D, Gehlert D (1989) Delayed c-fos proto-oncogene expression in the rat hippocampus induced by transient global cerebral ischemia: an in situ hybridization study. Brain Res 484:393-398.

Keller-Wood M, Dallman M (1984) Corticosteroid inhibition of ACTH secretion. Endocrinol Rev 5:1-24.

Kornhauser JM, Nelson DE, Mayo KE, Takahasi JS (1992) Regulation of Jun-B messenger RNA and AP-1 activity by light and a circadian clock. Science 255:1581-1584.

Krystal JK, Kosten FR, Southwick S, Mason JW, Perry BD, Giller EL (1989) Neurobiological aspects of PTSD: review of clinical and preclinical studies. Behav Ther 20:177-198.

Le F, Wilce PA, Hume DA, Shanley BC (1992) Involvent of $\gamma$-aminobutyric acid and $N$-methyl-D-aspartate receptors in the inhibitory effects of ethanol on pentylenetetrazole-induced c-fos expression in rat brain. J Neurochem 59:1309-1315.

Loyd C (1980) Life events and depressive disorder. II. Events as precipitating factors. Arch Gen Psychiatry 37:541-548.

Maleeva NE, Ivolgina GL, Anokhin KV, Limborskaya SA (1989) Analysis of the expression of the c-fos proto-oncogene in the rat cerebral cortex during learning. Genetika 25:1119-1121.

Mason JW (1959) Plasma 17-hydroxycorticosterone levels during electrical stimulation of the amygdaloid complex in conscious monkeys. Am J Physiol 196:44-48.

Mason JW (1968) A review of psychoendocrine research on the sympathetic-adrenal medullary system. Psychosomatic Med 30:631-653.

Morgan JI, Curran T (1991) Stimulus-transcription coupling in the nervous system: involvement of the inducible proto-oncogenes fos and jun. Annu Rev Neurosci 14:421-451.

Morgan PF, Nadi NS, Karanian J, Linnoila M (1992) Mapping brain structures activated during ethanol withdrawal: role of glutamate and NMDA receptors. Eur J Pharmacol 225:217-223.

Muller R, Bravo R, Burckhardt J, Curran T (1984) Induction of c-fos gene and protein by growth factors precedes activation of c-myc. Nature 312:716-720.

Munck A, Guyre PM, Holbrook NJ (1984) Physiological functions of glucocorticoids in stress and their relation to pharmacological actions. Endocrinol Rev 5:25-44.

Natelson BH, Ottenweller JE, Cook JA, Pitman D, McCarty R, Tapp 
WN (1988) Effect of stressor intensity on habituation of the adrenocortical response. Physiol Behav 43:41-46.

Noda K, Minotagawa Y, Higuchi T (1991) Effects of hippocampal neurotoxicant trimethylin on corticosterone response to swim stress and glucocorticoid binding capacity in the hippocampus in rats. Jpn J Psychol Neurol 45:167-168.

Pezzone MA, Lee WS, Hoffman G, Rabin BS (1992) Induction of c-fos immunoreactivity in the rat forebrain by conditioned and unconditioned aversive stimuli. Brain Res 597:41-50.

Pezzone MA, Lee WS, Hoffman GE, Pezzone KM, Rabin BS (1993) Activation of brainstem catecholaminoergic neurons by conditioned aversive stimuli as revealed by c-Fos immunoreactivity. Brain Res 608:310-318.

Pitman DL, Ottenweller JE, Natelson BH (1990) Effect of stressor intensity on habituation and sensitization of glucocorticoid responses in rats. Behav Neurosci 104:28-36.

Ramsey JM (1982) Basic pathophysiology: modern stress and the disease process. Palo Alto, CA: Addison Wesley.

Redmond DE, Huang YH (1979) Current concepts. II. New evidence for a locus coeruleus-norepinephrine connection with anxiety. Life Sci 25:2149-2162.

Richardson-Morton KD, Van de Kar LD, Brownfield MS, Bethea CL (1989) Neuronal cell bodies in the hypothalamic paraventricular nucleus mediate stress-induced renin and corticosterone secretion. Neuroendocrinology 50:73-80.

Rosen KM, McCormack MA, Villa-Komarow L, Mower GD (1992) Brief visual experience induces immediate early genes expression in the cat visual cortex. Proc Natl Acad Sci USA 89:5437-5441.

Sagar SM, Sharp FR, Curran T (1988) Expression of c-fos protein in brain: metabolic mapping at the cellular level. Science 240:13281330.

Sakellaris PC, Vernikos-Danellis J (1975) Increased rate of response of the pituitary-adrenal system in rats adapted to chronic stress. Endocrinology 97:592-602.

Sambrook J, Fritsch EF, Maniatis T (1989) Molecular cloning. A laboratory manual. Cold Spring Harbor, NY: Cold Spring Harbor Laboratory.

Saphier D, Feldman S (1987) Effects of septal and hippocampal stimuli on paraventricular nucleus neurons. Neuroscience 20:749-755.

Sapolsky RM, Krey LC, McKewen BS (1984) Glucocorticoid-sensitive hippocampal neurons are involved in terminating the adrenocortical stress response. Proc Natl Acad Sci USA 81:6174-6177.

Sassone-Corsi P, Sisson JC, Verma IM (1988) Transcriptional autoregulation of the proto-oncogene fos. Nature 334:314-319.
Sawchenko PE (1991) The final common path: issues concerning the organization of central mechanisms controlling corticotropin secretion. In: Neurobiology and neuroendocrinology of stress (Brown MR, Rivier C, Koob G, eds). New York: Dekker.

Schreiber SS, Tocco G, Shors TJ, Thompson RF (1991) Activation of immediate early genes after acute stress. Mol Neurosci 2:17-20.

Seggie J, Uhlir I, Brown GI (1973) Adrenal stress responses following septal lesions in the rat. Neuroendocrinology 16:225-236.

Selye $H$ (1936) Thymus and adrenals in the response of the organism to injuries and intoxications. Br J Exp Pathol 17:234-248.

Selye $H$ (1952) The story of the adaptation syndrome. Montreal: Acta. Sharp FR, Sagar SM, Hicks K, Lowenstein D, Hisanaga K (1991) c-fos mRNA, Fos, and Fos-related antigen induction by hypertonic saline and stress. J Neurosci 11:2321-2331.

Sheng M, Greenberg ME (1990) The regulation and function of c-fos and other immediate early genes in the nervous system. Neuron 4:477485.

Smith MA, Kling MA, Whitfield HJ, Brandt HA, Demitrack MA, Geracioti TD, Chrousos GP, Gold PW (1989) Corticotropin releasing hormone: from endocrinology to neurobiology. Horm Res 31:66-71.

Smith MA, Banerjee S, Gold PW, Glowa J (1992) Induction of c-fos mRNA in rat brain by conditioned and unconditioned stressors. Brain Res 578:135-141.

Sonnenberg JL, Macgregor-Leon PF, Curran T, Morgan JI (1989) Dynamic alterations occur in the levels and composition of transcription factor AP-1 complexes after seizure. Neuron 3:359-365.

Stone EA, Zhang Y, John S, Filer D, Bing G (1993) Effect of locus coeruleus lesions on c-fos expression in the cerebral cortex caused by yohimbine injection or stress. Brain Res 603:181-185.

Szafarczyk A, Alonso A, Ixart G, Malaval G, Assenmacher I (1985) Diurnal-stimulated and stress-induced ACTH release is mediated by ventral noradrenergic bundle. Am J Physiol 249:E219-E226.

Vernikos J, Dallman MF, Bonner C, Katzen A, Shinsako J (1982) Pituitary-adrenal function in rats chronically exposed to cold. Endocrinology 110:413-420.

Winston SM, Hayward MD, Nestler EJ, Duman RS (1990) Chronic electroconvulsive seizures down-regulate expression of the immediate early genes c-fos and c-jun in rat cerebral cortex. J Neurochem 54: $1920-1925$.

Worley PF, Christy BA, Nakabeppu Y, Bhat RV Cole AJ, Baraban JM (1991) Constitutive expression of zif268 in neocortex is regulated by synaptic activity. Proc Natl Acad Sci USA 88:5106-5110.

Yates E, Marsh D, Maran J (1980) The adrenal cortex. In: Medical physiology, 14th ed (Mountcastle V, ed). St. Louis: Mosby. 